\title{
A técnica de ERP: investigando a assimetria sujeito-objeto na interface sintaxe-semântica com EEG
}

\author{
The ERP technique: investigating the assimetry subject-object \\ in the syntax semantics interface with an EEG
}

\author{
Aniela Improta França \\ Juliana Novo Gomes \\ Universidade Federal do Rio de Janeiro - Rio de Janeiro - Rio de Janeiro - Brasil
}

$\diamond$

Resumo: Este trabalho trata da cronologia computacional no processamento de sentenças. Recentes pesquisas com potenciais bioelétricos relacionados a eventos (ERPs), usando frases com papéis temáticos invertidos sob a luz da Teoria da Ilusão Semântica, desafiam o pressuposto de que os processos sintático-semânticos estejam acoplados. Através de dois experimentos (voz ativa e passiva) testamos sentenças com papel temático invertido em três condições. Reestabelecemos uma correspondência direta entre modelos Sintaxe-Primeiro e o processamento de sentenças on-line, relacionando-os com recentes descobertas neurofisiológicas de que há duas vias de processamento, a via ventral, para palavras e itens coordenados e, a dorsal, para estruturas hierárquicas. Encontramos evidências em favor do modelo SintaxePrimeiro. Os potencias N400 e P600 parecem ser modulados pela assimetria sujeito-objeto, refletindo, respectivamente, a concatenação do argumento interno ao verbo e a integração do argumento externo.

Palavras-chave: Sintaxe-semântica; Linguística; Neurociência da Linguagem; EEG/ERPs, Metodologia Experimental

\begin{abstract}
This paper is about the computational chronology of sentence processing. Using rolereverse sentences, recent ERPs studies, in light of Semantic Illusion Theory, have challenged the assumption that syntactic-semantic processes are coupled. We ran two ERP experiments (active and passive voice) using event-related brain potentials (ERPs) in role-reversed sentences in three conditions, trying to reestablish a direct correspondence between syntax-first models and on-line sentence processing and relating them to new neurophysiological findings of two processing pathways, a ventral and a dorsal, the first for words and coordinated items and the second for hierarchical structures. We found evidence in favor of a syntax-first account. The N400 and P600 appear to be modulated by the subject-object asymmetry, reflecting, respectively, the merge of the internal argument with the verb and, the integration of the external argument.
\end{abstract}

Keywords: Syntax-semantics; Linguistics; Neuroscience of Language; EEG/ERPs, Experimental Methodology 


\section{Introdução}

A natureza distributiva do processamento cortical é ressaltada quando entendemos que o output de um milhão de células ganglionares pode recrutar a atividade de bem mais de um bilhão de neurônios corticais, vindos de algum lugar dos lobos occipital, parietal e temporal. De alguma forma, essa atividade cortical generalizada é combinada para formar um todo em que não se percebem emendas: enfim uma percepção unificada do mundo. (BEAR; CONNERS; PARADISO, 2006, p. 269)

A principal tarefa dos sistemas neuronais é construir no cérebro representações do mundo a nossa volta, de modo que estas representações possam ser manipuladas pelos nossos processos cognitivos.

A primeira etapa desta tarefa consiste em traduzir os fenômenos físicos, capturados pelos sentidos para a linguagem dos neurônios ${ }^{1}$. A grande diversidade de estímulos físicos deve ser reduzida para um único código, o potencial de ação, uma onda eletroquímica que resulta da variação do potencial elétrico na membrana das células neurais receptoras. Assim, durante a transdução sensorial, processo de transformação da energia elétrica que está presente na membrana plasmática dos receptores sensoriais, os estímulos físicos são recodificados em termos de efeitos sinápticos (LENT, 2008).

As sinapses são junções especializadas através das quais um neurônio manda sinais para outro e para células não neuronais, como músculos e gânglios. Fisicamente a sinapse é um pequeno espaço cheio de fluido, denominado fenda sináptica, que se coloca entre neurônios e promove a junção entre eles. De um lado desta fenda existe um neurônio pré-sináptico carregando informações elétricas no potencial de ação. Do outro lado da junção está o neurônio pós-sináptico que recebe a informação. O potencial de ação chega até o botão terminal do axônio do neurônio pré-sináptico, mas não consegue sair de lá sob a forma de eletricidade por que há fluido (neurotransmissores) na fenda sináptica. A sinapse é eletroquímica justamente porque depois de o potencial de ação viajar ao longo do axônio do neurônio e atingir o terminal pré-sináptico, ele provoca a liberação na fenda de uma pequena quantidade de moléculas de neurotransmissores: acetilcolina, norepinefrina,

\footnotetext{
1 O neurônio pode ser considerado a unidade básica de processamento informacional do cérebro e do sistema nervoso central. É a célula do sistema nervoso responsável pela transmissão do impulso nervoso. Existem cerca de 100 bilhões de neurônios no sistema nervoso humano. Os neurônios são constituídos pelas seguintes partes: (i) corpo celular; já o núcleo da célula é composto por (ii) dendritos - ramos extensos que vêm do exterior da membrana do neurônio e recebem sinais elétricos de outros neurônios; (iii) axônio - um prolongamento do neurônio e (iv) telodendro - uma ramificação terminal do axônio, por onde o impulso passa de um neurônio para o outro ou vai para outro órgão.
}

epinefrina, histamina, glutamato e serotonina, dentre outros. Diferentemente do potencial de ação, essas moléculas podem se propagar pelo fluido até a membrana pós-sináptica, e lá se ligam a moléculas receptoras específicas, que ficam localizadas na membrana plasmática do neurônio pós-sináptico, no lado oposto da fenda sináptica (Figura 1).

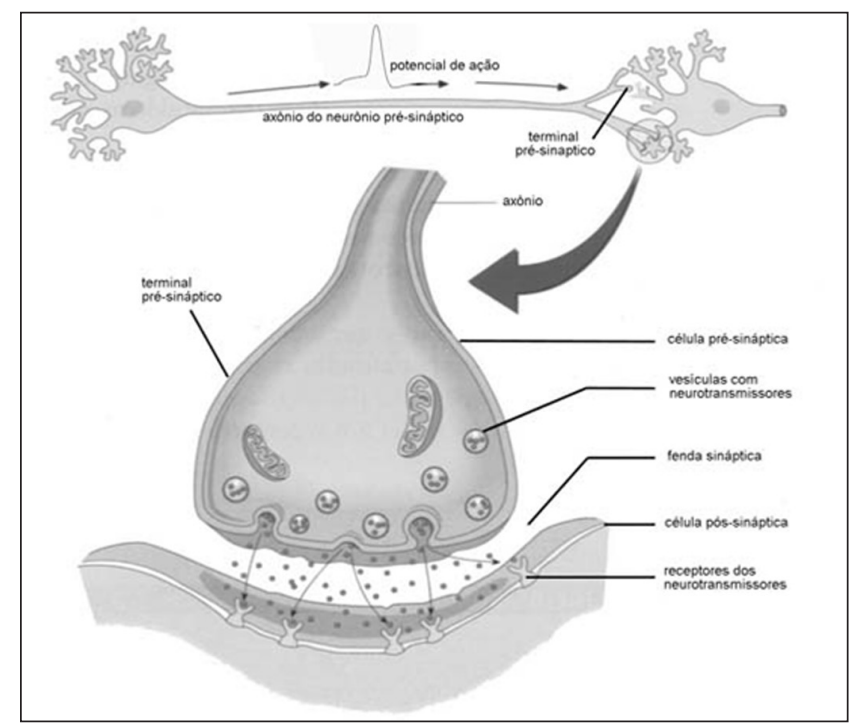

Figura 1. Transferência dos neurotransmissores da membrana présináptica para a membrana pós-sináptica (disponível em: <http:// www.geocities.ws/ctv10ano/sinapse.jpg >)

Diferentes neurotransmissores podem ser liberados em diferentes condições. Além disso, dependendo do neurotransmissor liberado, o potencial de ação que será deflagrado no neurônio seguinte pode ser repetido, inibido ou modificado. É esta diversidade na interação sináptica que permite que comportamentos diferentes sejam desencadeados por um único estímulo. Os potenciais vem em série, um depois do outro, e o fluxo deles funciona como código digital a serem decifrado pelo processamento cortical. Em uma micro-perspectiva, este é o processo responsável pelo funcionamento do cérebro (Para uma revisão com animações em flash $c f$. http://www.mind. ilstu.edu/curriculum/modOverview.php?modGUI=232).

\section{O uso de EEG-ERP}

Demorou bastante tempo na história da neurologia para que a eletricidade cerebral fosse compreendida e monitorada. A primeira técnica utilizada para esta finalidade utilizava um eletroencefalógrafo (EEG), um instrumento desenvolvido por Hans Berger (1873-1941), psiquiatra alemão, que em 1924 conectou dois eletrodos ao couro cabeludo de um paciente e detectou uma pequena corrente elétrica. $\mathrm{Na}$ verdade Berger era obcecado 
pela ideia de correlacionar a temperatura do cérebro a processos psíquicos. Porém, como sua pesquisa não logrou êxito, Berger passou a se dedicar aos métodos de monitoração da eletricidade cerebral. Assim, desenvolveu o eletroencefalógrafo (EEG) que permitiu um maior conhecimento das ondas emitidas pelo cérebro: Beta, Alfa, Teta, Delta, Gama relacionadas a diferentes estados de consciência (Figura 2).

$\mathrm{O}$ ritmo das ondas equivale ao número de ciclos por segundo que, por sua vez são respostas a vários tipos de fenômenos eletrofisiológicos refletindo numerosas operações neurais. A eletroencefalografia permite a aquisição e armazenamento dos sinais bioelétricos, através do registro contínuo da atividade eletrocortical colhida por meio de eletrodos fixados em diversos pontos no couro cabeludo. Cada um desses eletrodos é colocado em um ponto específico, que está diretamente relacionado a uma área do córtex cerebral. Estes pontos no couro cabeludo são chamados de derivações. A ponta do eletrodo é capaz de capturar a atividade elétrica de milhares de neurônios. A outra ponta do eletrodo está ligada ao EEG que funciona como um gravador de muitos canais (Figura 3). Ele grava simultaneamente o fluxo da atividade elétrica capturado em cada derivação e manda uma representação gráfica dessa atividade para a tela do computador. Qualquer flutuação de tensão $(\mu \mathrm{V})$ capturada é registrada e gravada pelo EEG, permitindo uma leitura online e também uma avaliação posterior da atividade elétrica em cada derivação ao longo do tempo. O EEG traça linhas com a atividade elétrica adquirida por cada eletrodo fixado em cada ponto no escalpo.

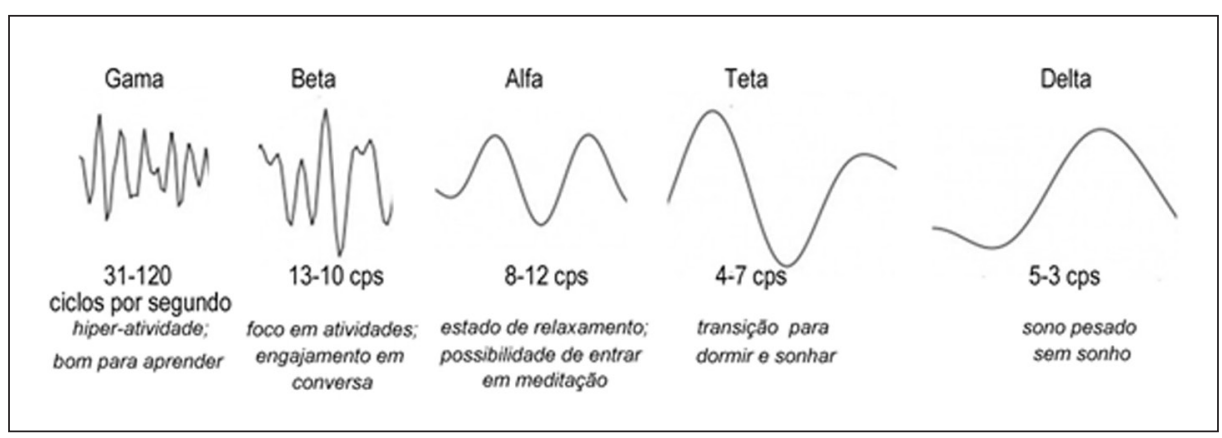

Figura 2. As ondas cerebrais e seus ritmos (ciclos por segundo). Retirado de França (2015, no prelo).

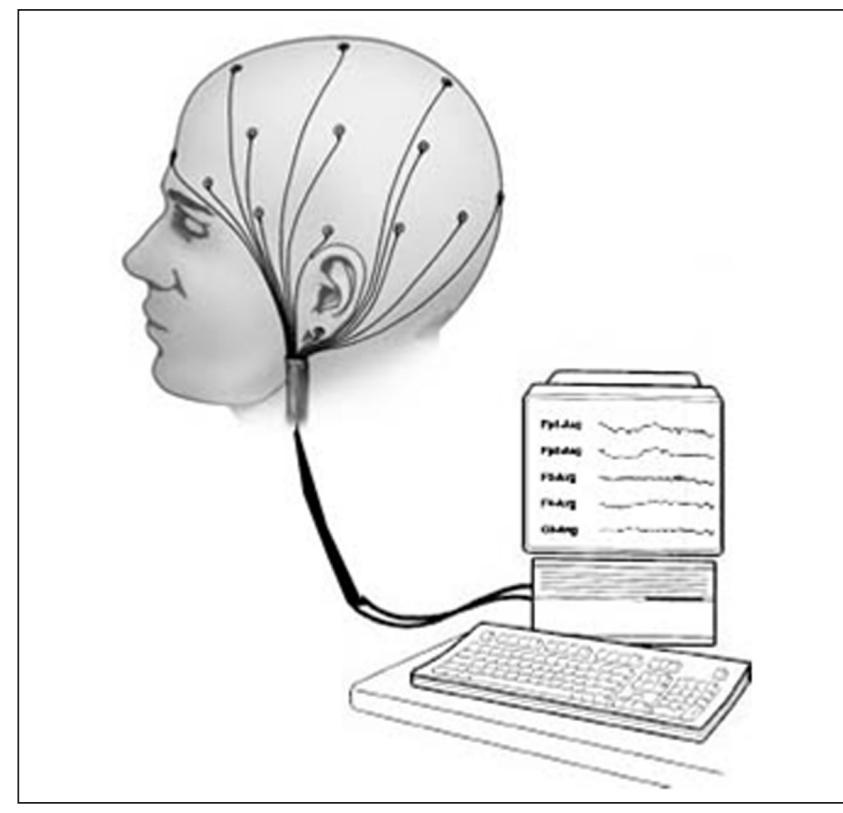

Figura 3. Pessoa sendo monitorada por teste eletroencefalográfico. (Disponível em: <http://www.mayoclinic.org/testsprocedures/eeg/multimedia/eeg-brain-activity-/img-20005915>, adaptado)

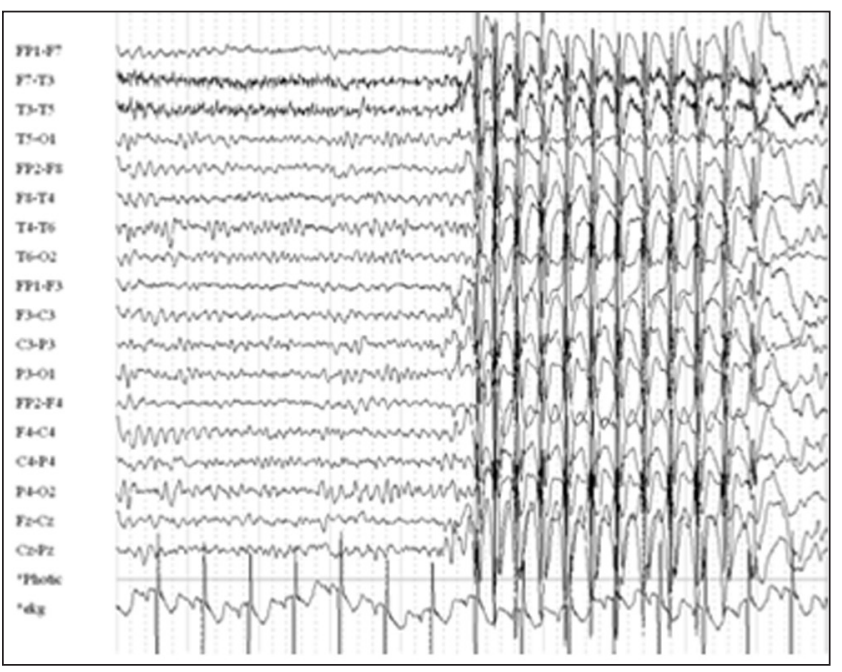

Figura 4. EEG de uma criança exibindo padrão de atividade elétrica normal à esquerda em contraste com trecho à direita que mostra atividade elétrica excessiva, durante uma convulsão. Disponível em: <http://buffaloepilepsy.org/evaluation.html>. 
Assim, monitorando as linhas paralelas do traçado online do EEG, cada linha relativa a uma derivação, pode-se identificar alguma discrepância do padrão de atividade normal em uma derivação. (BEAR; CONNERS; PARADISO, 2006). Por exemplo, lendo o EEG na Figura 4, da direita para esquerda, ou seja, no sentido do sinal mais antigo para o mais recente, é possível identificar um trecho com atividade elétrica excessiva e desordenada. Esse trecho está relacionado ao período de uma convulsão. Mais à esquerda o padrão da atividade elétrica aparece voltando ao normal, sinalizando que a convulsão cessou.

Uma peculiaridade do aparelho de EEG é que ele filtra e amplifica as ondas ao longo do tempo e permite que elas possam ser avaliadas depois da coleta. Esse processo confere à técnica uma excelente precisão temporal, em milissegundos. Porém a técnica não oferece boa resolução espacial. Isso acontece porque, antes de chegarem ao escalpo, as ondas têm que passar por muitas camadas de tecido não-neuronal no interior do cérebro. As ondas ricocheteiam no interior do cérebro e, quando se superficializam e são capturadas pelos eletrodos no escalpo, não mantêm proximidade espacial com a fonte elétrica que lhes deu origem. Além disso, o sinal capturado também perde força no caminho até ser capturado no couro cabeludo. É por isso que os sinais elétricos devem ser amplificados para serem examinados, e a máquina de EEG já vem equipada para fazer isso.

No teste de EEG simples, utilizado no diagnóstico de epilepsias e de uma gama de outras disfunções neurológicas, todo o cérebro é avaliado com o indivíduo em repouso, dormindo ou efetuando mobilizações diminutas como piscar o olho. Ou seja, o EEG foi desenhado para analisar a eletricidade cortical como pano de fundo, sem relacioná-la a uma atividade cognitiva.

Em contraste a técnica de extração de potenciais relacionados a eventos (EEG/ERP) foi desenvolvida exatamente para que se possa relacionar a reação bioelétrica a um estímulo específico de origem cognitiva, reação essa geralmente percebida só em uma porção do couro cabeludo. Este teste tem muito interesse para a pesquisa nas neurociências cognitivas.

Assim, os ERPs são respostas do sistema nervoso com grande resolução temporal à estimulação motora ou sensorial. Para a extração poder acontecer, usa-se o EEG cru, acrescentado de alguns procedimentos técnicos que serão descritos. Além das linhas no traçado do EEG que correspondem à atividade elétrica capturada pelos eletrodos, no ERP se utiliza um canal extra, chamado canal de anotação, em que se pode marcar o momento exato em que o indivíduo é estimulado por um evento cognitivo de interesse (LUCK, 2005).

Esta técnica de sincronizar ou acoplar no tempo uma parte do estímulo do teste com a resposta elétrica do voluntário é feita através da colocação de um gatilho (usa-se frequentemente o termo em inglês trigger), codificado como uma onda quadrada, produzida pelo computador (Figura 5).

Os ERPs são compostos por uma sequência de ondas caracterizadas por latência (o tempo que a onda demora para se formar, medido em milissegundos), amplitude (a altura do pico da onda, medido em microvolts) e polaridade (para cima negativa e para baixo positiva). Porém, não é possível, por exemplo, identificarmos a reação cortical de uma única pessoa estimulada por um único item de uma condição experimental, por exemplo a reação do voluntário 1 à leitura da sentença João comeu um carro em comparação à reação do voluntário 2 à leitura da sentença João comeu um bolo. Se estamos interessados em estudar os efeitos da concatenação incongruente entre o verbo e objeto precisamos somar a reação cognitiva de vários voluntários com idades semelhantes, estimulados por vários eventos linguísticos do mesmo tipo. Para que possamos visualizar um ERP, relativo a uma concatenação

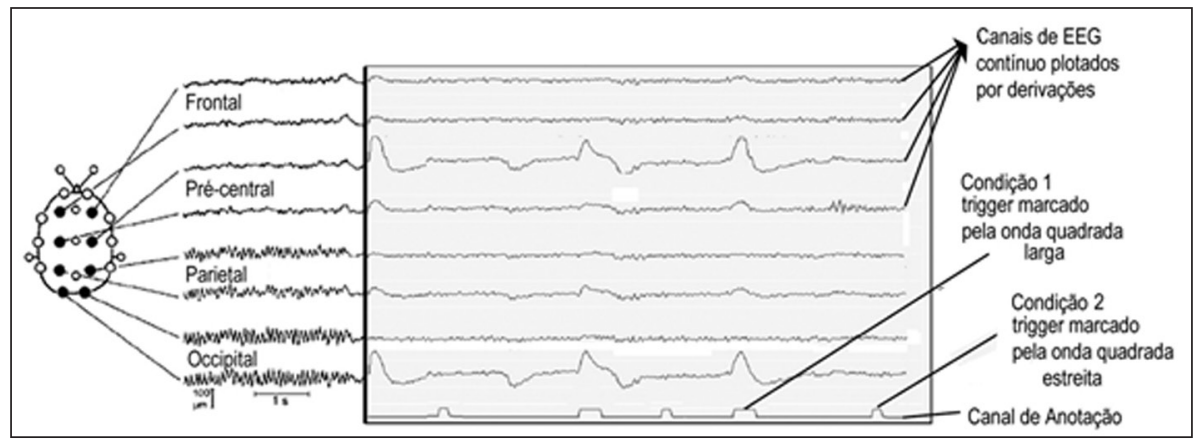

Figura 5. Traçado contínuo do EEG nas derivações. Na última linha do traçado está visível o canal de anotação, marcado com as ondas quadradas, que permitem que se identifique as condições relacionadas aos trechos de onda. A identificação é essencial para cortar as épocas antes da operação de promediação ser executada. 
entre verbo e o complemento temos que somar os trechos do EEG corrido onde se encontram as palavras de interesse, no caso verbo + objeto. Estes trechos de interesse são chamados de épocas ${ }^{2}$.

Depois de colher todas as épocas, é preciso tratálas. Para suprimir o ruído e fazer aflorar apenas a onda relacionada ao evento (ERP), a técnica da promediação (grand-averaging) deve ser utilizada. Esta técnica consiste em efetuar a média coerente do mesmo trecho acoplado no tempo, para cada condição do teste (Figura 6). O efeito principal da promediação é o de aumentar a relação sinal/ruído (SNR), permitindo a visualização do efeito específico, neste caso, de um estímulo linguístico. Desta forma, a promediação é usada para diminuir a relação sinal-ruído (SN) encontrada nos sinais originais não amplificados (LUCK, 2005; GESUALDI; FRANÇA, 2011).

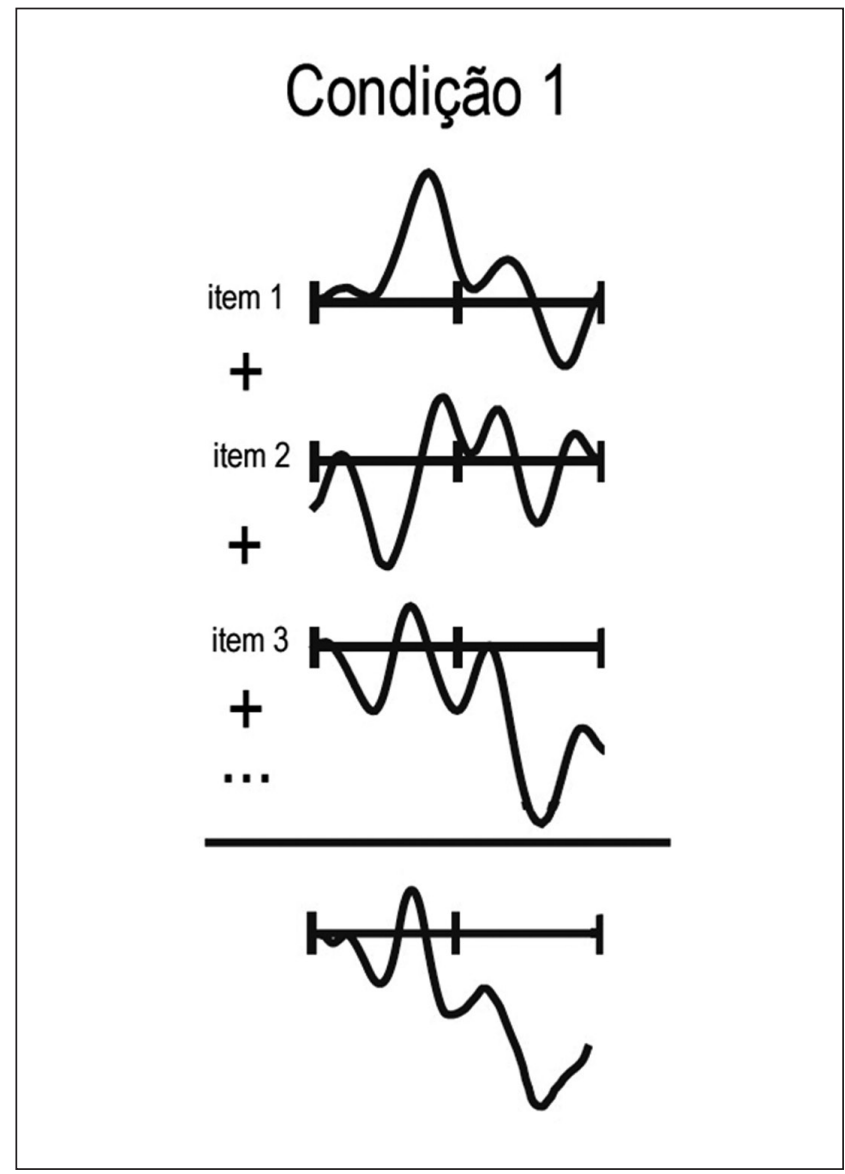

Figura 6. Promediação (a soma de vários trechos de EEG de uma mesma condição experimental onde está a palavra de interesse)

\section{Os ERPs Linguísticos}

Os ERPs começaram a ser utilizados na década de 80 , por psicólogos. Isso significa que a Neurociência da Linguagem herdou os protocolos experimentais de estimulação já bem utilizados na Psicologia Cognitiva e na Psicolinguística e os incrementou com o monitoramento neurofisiológico.

Embora a linguística teórica tenha uma história longa e bem sucedida de trabalhos que alimentam modelos detalhados e abrangentes acerca da compreensão da linguagem, foi somente recentemente que a neurociência começou a investigar como se dá o processamento da linguagem on-line. Este campo se situa no cruzamento entre, pelo menos, três ciências: a neurociência, a biologia e linguística. Estes compõem o que Chomsky chamou de biolinguística.

A Biolinguistica, [...] toma a faculdade da linguagem como um componente do binômio mente/ cérebro, assim como os módulos de percepção visual, organização da ação motora, etc. Sair dos procedimentos analíticos rumo à Biolinguística enriquece muito a variedade de evidências que sobre o estudo de cada língua a ponto de incluir a aquisição, a neurociência, as dissociações, e muito mais, e também o que é aprendido a partir do estudo de outras línguas, no pressuposto de que a capacidade para a linguagem se baseia em propriedades biológicas. (CHOMSKY, 2012, p. $3 \mathrm{~ms}$ )

Parece ter havido, a partir de 2010, um consenso maior no que diz respeito à interdisciplinaridade, a fim de lidar com todas as questões ainda sem resposta sobre a cognição da linguagem. O objetivo maior desta fusão é o de parear processos identificados e explicados formalmente pelas teorias linguísticas aos mecanismos cerebrais subjacentes aos sistemas cognitivos.

A metodologia discutida aqui - EEG/ERP oferece uma importante contribuição para a linguística experimental porque traz sinais do funcionamento sutil da arquitetura da linguagem on-line, mapeando a atividade eletrocortical com resolução de milissegundos, de forma a permitir uma correspondência com as computações descritas pela Teoria Linguística.

Dois ERPs entre vários vem sendo estudados com essa metodologia em um grande número de línguas: o N400 e o P600. O N400 é um componente negativo com pico de maior amplitude em torno dos $400 \mathrm{~ms}$ após a estimulação, sendo o nome N400 devido ao seu caráter negativo $(\mathrm{N})$ e a sua latência $(400 \mathrm{~ms})$. Já o P600 é uma onda positiva, cujo pico de maior amplitude se dá a cerca de $600 \mathrm{~ms}$ após estimulação. Em estudos com ERP, o N400 vinha sendo relacionado principalmente a

\footnotetext{
As épocas são trechos funcionais no contínuo do EEG, onde se encontram
as reações às palavras de interesse. Elas são acopladas no tempo

As épocas são trechos funcionais no contínuo do EEG, onde se encontram
as reações às palavras de interesse. Elas são acopladas no tempo cortadas do contínuo para serem estudadas mais profundamente.
} 
processos semânticos, do tipo (i) e o P600 a processos sintáticos (HAGOORT, 2003).

A partir do ano 2000, alguns estudos contrastando sentenças semanticamente mal formadas do tipo (i) e (ii), mostraram resultados não-canônicos que parecem desafiar a dicotomia clássica entre N400 e P600.

(i) The patient examined the doctor.

O paciente examinou o médico.

(ii) The doctor was examined by the patient.

$\mathrm{O}$ médico foi examinado pelo paciente.

Esses novos achados parecem apontar para um P600 semântico (HOEKS; STOWE ; DOEDENS, 2004; KIM; OSTERHOUT, 2005; KOLK et al, 2003;. KUPERBERG et al, 2003a, 2006, 2007; . LAU et al, 2006;. STROUD; COLIN PHILLIPS, 2010; VAN HERTEN; KOLK; CHWILLA, 2005a; VISSERS; CHWILLA; KOLK, 2007).

De acordo com essa literatura, a inversão de papeis temáticos prováveis nas sentenças (i) e (ii) causam um tipo de "Ilusão Semântica" (Semantic Illusion) que poderia ser marcada por um P600.

$\mathrm{O}$ efeito singular seria o resultado de uma "leitura de superfície" resultante de heurística do processamento. Ao acessar o conteúdo das raízes dos argumentos, o parser prescindiria de estruturas sintáticas para indicar as posições de sujeito e objeto. Assim, somente as informações superficiais seriam suficientes para o entendimento do cômputo geral dessas sentenças: Ao lerse médico e paciente ficaria claro quem examinou quem, sem se precisar da informação sintática. Assim, alguns autores estudando o processamento de estruturas com papel temático invertido, tanto na voz ativa, quanto na voz passiva relatam que a inversão ao invés de provocar o N400 canônico, elicia um potencial que passou a ser chamado de P600 semântico.

Não obstante, essa alternativa de processamento de superfície da dita Ilusão Semântica, contrasta com a Hipótese Sintaxe-Primeiro, que aposta que o processamento é inconsciente e involuntário e que segue um algoritmo que promove "sintaxe de cima a baixo" durante todo o processamento (MARANTZ, 1997).

Neste trabalho, reportamos os resultados de dois experimentos que figuram em um estudo que contrastou essas duas previsões (GOMES, 2014). Note-se que esta investigação não é trivial, pois existem dados científicos que suportam as duas teorias concorrentes acerca da dicotomia N400-P600:

Se anomalias semânticas dão origem a uma resposta P600 apenas quando há uma interpretação plausível da estrutura profunda, então isto sugere que a estrutura profunda desempenha um papel importante no processamento de frases. Por outro lado, se o efeito do P600 é induzido por anomalias semânticas, independentemente da disponibilidade de uma interpretação plausível da estrutura profunda, então, os efeitos de P600 encontrados em frases com papel temático invertido seriam compatíveis com a ideia de que as informações da estrutura profunda não têm papel na computação sintática. (CHOW; PHILLIPS, 2013, p. 78)

Esta competição teórica define um objeto de investigação bastante válido e atual: oferecer provas, além das já apresentadas, para caracterizar os estágios relativos ao processamento de sentenças envolvendo papel temático invertido. O EEG-ERP, com sua precisão temporal foi o arsenal tecnológico escolhido para tal verificação.

\section{Contribuições dos métodos de imagem funcional para um modelo de processamento}

Recentemente, a utilização de um novo paradigma experimental utilizando a técnica da ressonância magnética funcional (fMRI-DTI ${ }^{3}$ ) para obter imagens do cérebro vêm sendo capaz de apontar efeitos ainda mais sutis subjacentes aos componentes elétricos relativos ao processamento de sentenças (para uma revisão, BAUMGAERTNER; WEILLER; BÜCHEL, 2002; LAU; PHILLIPS; POEPPEL, 2008).

De acordo com esses achados experimentais, o acesso lexical e a coordenação seriam fenômenos processados em um local diferente no córtex do que os processos sintáticos hierárquicos relacionados ao processamento de sentenças. Assim, um modelo recentemente proposto por Angela Friederici define duas vias de processamento: dois conjuntos de vias ventrais ligando as áreas cerebrais BA 45, pela BA 47, até o ATL (lobo temporal anterior) e o MTG (giro medial temporal); e uma via de ligação dorsal de BA 44 para o PTG (giro temporal posterior) (FRIEDERICI et al, 2011; BERWICK et al, 2013; FRIEDERICI, 2011) (Figura 7).

\footnotetext{
Ressonância Magnética Funcional $(f M R I)$ possibilita o mapeamento do fluxo sanguíneo que abastece áreas neuronais com direito de oxigênio durante a atividade neuronal em relação a um evento (por exemplo, a apresentação de uma frase). Isto é feito através da criação de campos de força magnética que desestabilizam certos elementos atômicos no sangue, e medem o retorno destes elementos ao seu estado estável. A DTI (Diffusion Tensor Imaging) é uma aplicação concomitante ao exame de fMRI que permite que as imagens por ressonância magnética possam também mostrar as conexões (cápsulas de fibras) entre áreas corticais remotas.
} 


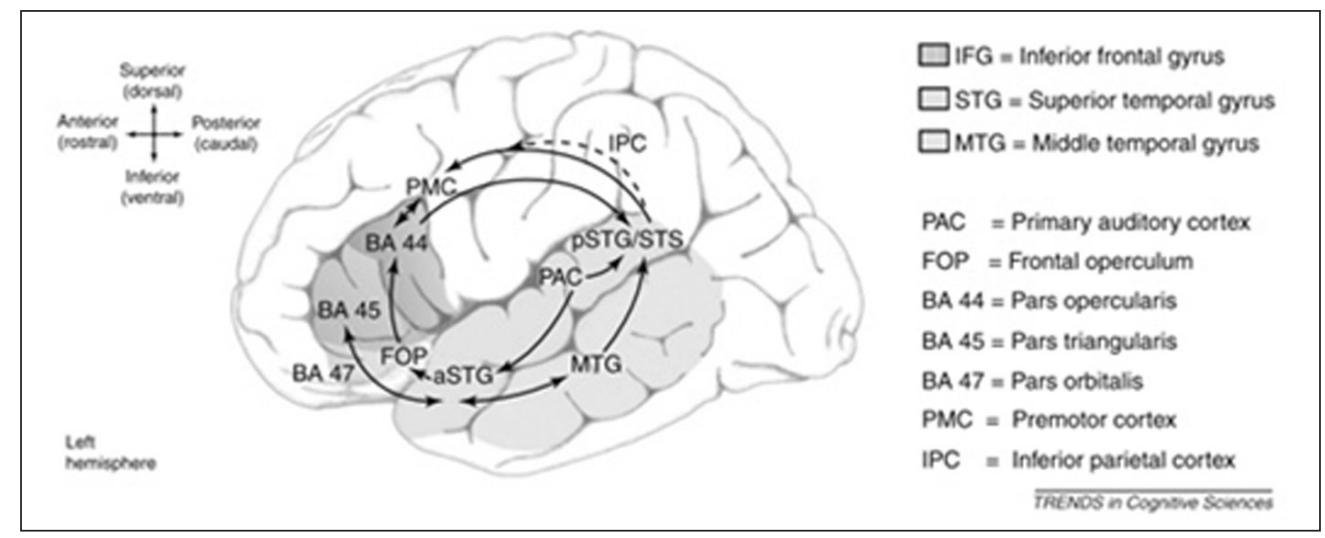

Figura 7. Vias de processamento da linguagem de acordo com o modelo proposto em Friederici et al. (2011, p. 263).

De acordo com este modelo, os conjuntos das vias ventrais seriam utilizados no acesso lexical de palavras soltas ou coordenadas. No entanto, os estímulos linguísticos testados até o momento não permitem conclusões acerca da natureza exata dos itens na via ventral, mas, uma vez que haja processamento morfológico e computação dentro das palavras, aventamos, neste trabalho, a hipótese de que a via ventral realizaria operações de concatenação interna a palavras e frases que não implicam na atribuição de papel temático, ou seja, que não envolvam um atribuidor de papel temático, como um verbo ou uma preposição. Em contraste, a via dorsal seria responsável pelo processamento hierárquico envolvendo uma computação sintática complexa.

Se isso for verdade, o processamento do argumento externo, que em inglês aparece primeiro nas sentenças na voz ativa, se daria através da via ventral como uma palavra solta. Em seguida haveria o processamento do verbo e seu complemento através da via dorsal, que processa hierarquicamente os conteúdos. Só então, depois de concatenado o verbo-objeto haveria a concatenação final do sujeito com este conjunto também pela via dorsal.

\section{Introdução aos Experimentos}

Com este modelo anátomo-funcional como pano de fundo, propusemos dois experimentos utilizando a metodologia de ERP, cuja hipótese de trabalho para ser testada é a de que exista uma hierarquia entre o processamento do argumento externo (sujeito) e o interno (objeto) e que ela privilegie a concatenação de verboobjeto: a assimetria sujeito-objeto.

Com um teste com tamanha acuidade temporal como o EEG-ERP, essa assimetria poderia ser captada ao longo do processamento de uma sentença através dos potenciais elétricos N400 e P600. Assim, a ideia é a de que em uma língua como o Inglês ${ }^{4}$, que é primordialmente SVO, o primeiro DP (sujeito) encontrado pelo falante seja processado como uma palavra solta. Ou seja seria processado pela via ventral e ficaria retido na memória de trabalho. A seguir haveria a concatenação entre o verbo e o argumento interno (objeto) que seriam processados pela via hierárquica, a via dorsal. Só então o primeiro DP (sujeito) seria integrado pelo algoritmo hierárquico, na via dorsal.

Assim, usamos o mapeamento dos estudos de ressonância para fundamentar um protocolo em EEGERP. Para investigar nossas hipóteses, analisaremos as manifestações eletro-corticais (N400 e P600) ao longo do curso temporal de processamento de frases em dois experimentos em separado. O experimento 1 é de voz ativa e o Experimento 2, de voz passiva, cada um com três condições (controle, papéis temáticos invertidos e objeto incongruente).

\section{Condições, estímulos e previsões}

No Experimento 1, o conjunto de estímulos foi dividido em três condições na voz ativa. Observe a Tabela 1:

Tabela 1. Experimento: Condições na Voz Ativa 5

\begin{tabular}{ll}
\hline $\begin{array}{c}\text { 1. Condições } \\
\text { - Voz Ativa }\end{array}$ & \multicolumn{1}{c}{ Exemplos } \\
\hline 1a. Controle & $\begin{array}{l}\text { O delegado prendeu o ladrão em flagrante. } \\
\text { O medico examinou o paciente na emergência. }\end{array}$ \\
$\begin{array}{cl}\text { 1b. Papéis temáticos } \\
\text { invertidos }\end{array}$ & $\begin{array}{l}\text { O ladrão prendeu o delegado em flagrante. } \\
\text { O paciente examinou o médico na emergência. }\end{array}$ \\
1c. Incongruente & $\begin{array}{l}\text { O delegado prendeu a alma em flagrante. } \\
\text { O medico examinou o lápis na emergência. }\end{array}$ \\
\hline
\end{tabular}

4 Este experimento foi desenvolvido em Língua Inglesa Americana em um projeto em conjunto com o Laboratório do Professor Albert Kim na Universidade do Colorado, nos Estados Unidos. Agradecemos ao Professor Kim pela co-orientação e colaboração neste trabalho.

5 Os experimentos apresentados aqui tiveram como participantes os alunos da University of Colorado, em Boulder, Colorado, USA. 
Segundo a hipótese aventada para a voz ativa, prevíamos que DPs, na posição de sujeito, como 'o delegado' seriam processados como uma frase atemática, que ficaria mantida na memória do leitor até que o verbo e o objeto, como 'prendeu o ladrão' fossem processados. Uma vez concatenados verbo e objeto, haveria então a integração do sujeito ao conjunto (verbo-objeto).

Com relação aos potenciais elétricos prevíamos que a concatenação verbo-objeto acontecesse na janela temporal do N400 (350 a 550ms). Assim sentenças do tipo (1a) e (1b) não deveriam gerar um N400, uma vez que a concatenação entre verbo-objeto é congruente: 'prendeu o ladrão' e 'prendeu o delegado', respectivamente em (1a) e (1b). Já nas sentenças do tipo (1c), o processamento do verbo e seu argumento interno por si só deverá eliciar um N400, devido à incongruência semântica observada em: 'prendeu a alma'.

Já a janela temporal do P600 (550 a 800ms) deve refletir processos mais tardios, como aqueles relacionados à integração do sujeito ao conjunto verbo-objeto. Prevemos então encontrar um componente mais tardio, como o P600, em (1b) e, apenas nesta série, uma vez que a integração do sujeito, 'o ladrão' ao conjunto 'prendeu o delegado', torna sentenças deste tipo semanticamente anômalas.

No Experimento 2, o conjunto de estímulos foi dividido em três condições na voz passiva. Observe a Tabela 2.

Tabela 2. Experimento: Condições na Voz Passiva

\begin{tabular}{ll}
$\begin{array}{l}\text { 2. Condições } \\
\text { - Voz Passiva }\end{array}$ & \multicolumn{1}{c}{ Exemplos } \\
\hline 2a. Controle & $\begin{array}{l}\text { O ladrão foi preso pelo delegado em flagrante. } \\
\text { O paciente foi examinado pelo médico na } \\
\text { emergência. }\end{array}$ \\
$\begin{array}{ll}\text { 2b. Papéis temáticos } \\
\text { invertidos }\end{array}$ & $\begin{array}{l}\text { O delegado foi preso pelo ladrão em flagrante. } \\
\text { Omédico foi examinado pelo paciente na }\end{array}$ \\
2c. Incongruente & $\begin{array}{l}\text { A alma foi presa pelo delegado em flagrante. } \\
\text { Olápis foi examinado pelo medico na }\end{array}$ \\
\hline
\end{tabular}

Para criar o Experimento 2, transformamos os estímulos do Experimento 1 em sentenças na voz passiva.

Prevíamos que na voz passiva, os DPs na posição inicial, como 'o ladrão' seriam incorporados à memória do leitor, já que o leitor não sabe que está lendo uma sentença na voz passiva, até que a morfologia de passiva seja integrada ao verbo. Quando esta morfologia for assimilada ao verbo, como em 'foi preso', o leitor seria então capaz de integrar o agente da passiva. Uma vez atribuídos os papeis temáticos, a sentença seria corretamente interpretada, enquanto 'o ladrão foi preso pelo delegado'. Porém, em (2b) e (2c) esta interpretação não deveria ser tão facilmente alcançada. As sentenças do tipo (2b), 'O delegado foi preso pelo ladrão' têm os papéis temáticos invertidos, por isso esperávamos algum tipo de efeito na janela temporal do P600, devido à integração do agente da passiva, o PP, 'pelo ladrão'. Um delegado é passível de ser preso, mas não é tão comumente aceito que um delegado seja preso por um ladrão.

Já nas sentenças do tipo (2c), 'A alma foi presa pelo delegado', esperávamos que sendo o primeiro DP (paciente) semanticamente anômalo, a integração deste elicitaria um efeito de N400.

\section{Participantes}

Um total de 15 indivíduos pagos (7 homens), alunos de graduação da Universidade de Colorado em Boulder, EUA participaram em cada um dos experimentos. Os participantes tinham idades entre 18-34 (média: 25,7). Todos os participantes eram destros. Os critérios de seleção exigiam que todos os participantes tivessem visão normal ou corrigida. Eles também deveriam ser falantes nativos de inglês americano. Um termo de consentimento informado aprovado pelo Comitê de Ética em Pesquisa da Universidade do Colorado foi obtido de todos os participantes antes da participação.

\section{Resultados do Experimento 1 - Voz Ativa}

Neste experimento foram testadas três condições: (1a) condição controle ('O delegado prendeu o ladrão em flagrante'); (1b) condição com papéis temáticos invertidos ('O ladrão prendeu o delegado em flagrante') e (1c) condição implausível semanticamente ('O delegado prendeu a alma em flagrante').

Uma vez que a condição (1b) é o meio-termo entre a controle (1a) e a condição implausível (1c), o nosso objetivo foi avaliar se (1b) seria interpretada de forma mais parecida com a série (1a) ou com a (1c) e por quê.

$\mathrm{Se}(1 \mathrm{~b})$ fosse processada de modo mais semelhante a (1c), que é uma frase incongruente, isso significaria que a informação semântica relativa ao sujeito estaria disponível desde o primeiro momento da derivação sintática. $\mathrm{O}$ evento de prender um delegado é possível, mas um ladrão não é um agente muito plausível para isso. Já que ao final da sentença, tanto o verbo, como complemento em (1a) e (1b) são plausíveis (existem seres que podem prender um ladrão e outros que podem prender um delegado), então, se (1b) for mais semelhantes a (1c) do que (1a), poderíamos afirmar que as informações dadas pelo sujeito são integradas imediatamente assim que o processamento é iniciado.

Em contraste, se (1b) fosse mais semelhante a (1a), que é a condição congruente, isso significaria que a informação semântica relativa ao sujeito não estaria 
presente desde o início do processamento da sentença. É importante notar que a concatenação entre o verbo e o seu complemento é plausível, o único empecilho à plausibilidade encontrado nesta condição diz respeito ao sujeito, o ladrão, e aos outros sujeitos usados para essa condição.

As médias das respostas corticais (ERPs) para o segmento crítico de cada condição estão dispostas na Figura 8.

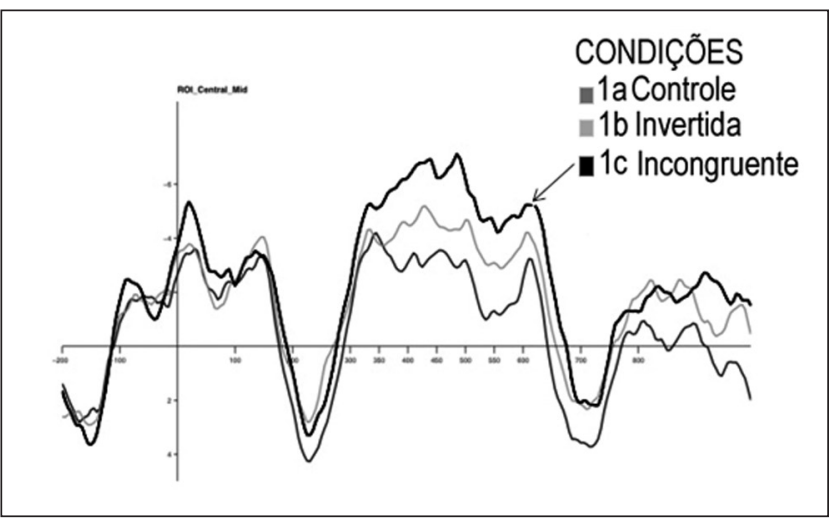

Figura 8. Médias de ERPs registadas em uma região central de interesse (ROI): para os DPs das três condições na voz ativa. Barra vertical marca o início da estimulação com a palavra crítica. Cada marcação de tempo representa $100 \mathrm{~ms}$ de atividade. Voltagem positiva está representada para baixo. Seta apontada para a condição 1c, para facilitar a identificação.

\section{Discussão do Experimento 1}

Conforme previsto, a comparação entre as condições (1a), controle, e (1c), incongruente, elicitou um N400 estatisticamente significativo, $\left[F(1,7)=p^{*}=.01\right]$. aos $400 \mathrm{~ms}$ após a estimulação com o argumento interno 'a alma' ('o delegado prendeu a alma'). Nenhum efeito estatístico foi encontrado para a janela do P600. Este resultado reforça a ideia de que o N400 esteja associado a anomalias semânticas, ao contrário do potencial P600.

A comparação entre as condições (1b), papéis temáticos invertidos, e (1c), incongruente, revelou um efeito estatístico de N400, $\left.F(1,7)=p^{*}=.007\right]$ e também um P600 $\left[F(2,13)=p^{*}=.048\right]$. O que é bastante revelador já que pode significar que o P600 é um componente em alguns casos associado a um processo de reanálise subsequente ao N400, como parece ser o caso aqui. O P600 parece, nestes casos, ser um efeito menos local do que o N400, por estar associado à informação relativa ao argumento externo e à sua integração com o complexo (verbo-objeto).

A última comparação feita procurava verificar se a inversão de papéis temáticos tornaria uma sentença implausível, como as sentenças da condição (1c) ou não. Comparamos a condição controle (1a) à condição (1b) com papéis temáticos invertidos e verificamos que nenhum N400 foi elicitado $[F(1,7)=p=.131]$. Desta maneira, poderíamos pensar que 'prendeu o ladrão' ou 'prendeu o delegado' é igualmente aceitável semanticamente.

Já a janela do P600, teve um efeito estatisticamente verificado $\left[F(2,13)=p^{*}=.030\right]$. Este achado parece ser o mais interessante levantado por este trabalho. Isto porque somado aos outros achados, corrobora com a hipótese de haver uma diferença de processamento entre o argumento interno e o externo. Uma vez que 'prendeu o delegado' não elícita um N400, podemos entender que há uma dificuldade maior para integrar o sujeito 'ladrão' em (1b), do que 'o delegado' em (1a), e essa diferença se dá na janela temporal do P600.

Com esse conjunto de achados, passaremos aos dados do Experimento 2.

\section{Resultados do Experimento 2 - Voz Passiva}

Assim como no Experimento 1, três condições foram testadas, todas na voz passiva: (2a) condição controle ('O ladrão foi preso pelo delegado em flagrante'); (2b) condição com papéis temáticos invertidos ('O delegado foi preso pelo ladrão em flagrante') e (2c) condição implausível semanticamente ('A alma foi presa pelo delegado em flagrante').

Assim, é possível verificar se (2b) é mais semelhante a (2a), que é a condição controle ou a (2c), que é uma frase incongruente, e por quê.

As médias das respostas corticais (ERPs) por regiões de interesse (ROIs) para o segmento crítico de cada condição estão dispostas na Figura 9.

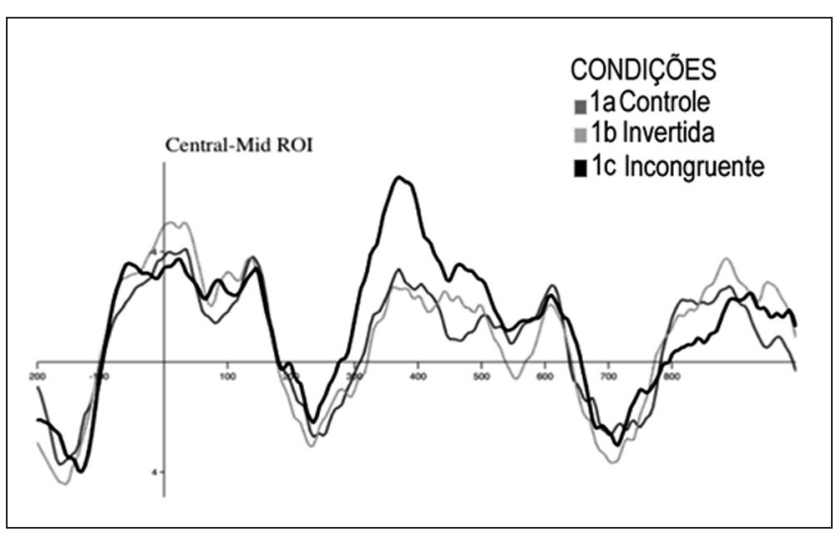

Figura 9. Médias de ERPs registradas para os DPs das três condições na voz passiva. Barra vertical marca o início da estimulação com a palavra crítica. Cada marcação de tempo representa $100 \mathrm{~ms}$ de atividade. Voltagem positiva está representada para baixo. 
Como podemos verificar na Figura 9, a condição incongruente (2c) foi dominada por respostas N400. Já a comparação entre a condição de controle ( $2 \mathrm{a}$ - linha preta) e a condição com papel temático invertido ( $2 b$-linha vermelha) não se comportou da mesma forma. Com relação ao P600, a comparação entre a condição de controle ( $2 \mathrm{a}$ - linha preta) e a condição com papel temático invertido ( $2 b-$ linha vermelha) obteve respostas mais positivas nas regiões posteriores, do que a comparação entre controle ( $2 a$ - linha preta) e a condição incongruente (2c-linha azul).

\section{Discussão do Experimento 2}

De acordo com as nossas previsões, a comparação entre as condições (2a), controle, e (2c), incongruente, eliciou um N400 estatisticamente significativo, $\left[F(1,7)=p^{*}=.011\right]$ aos $400 \mathrm{~ms}$ após a estimulação. Nenhum efeito estatístico foi encontrado na janela do P600. Este resultado reforça a ideia de que o N400 reflita anomalias semânticas, não só na voz ativa como também na voz passiva. Ele parece ser sensível à computação que integra o verbo ao seu complemento.

A comparação entre as condições (2b), papéis temáticos invertido, e (2c), incongruente, revelou um efeito estatístico de N400, $\left[F(1,7)=p^{*}=.011\right]$. Diferentemente dos resultados encontrados na voz ativa, esta comparação obteve apenas um P600 marginal, $\left[F(2,13)=p^{*}=.10\right]$. Quando comparado com os resultados encontrados na mesma comparação no Experimento 1, este resultado se torna ainda mais revelador, pois significa que uma mesma palavra pode ser sentida de forma diferente quando a voz verbal é outra (ativa vs passiva).

A última comparação feita, entre as condições (2a), controle, e (2b), papéis temáticos invertido, não revelou um efeito estatístico de $\mathrm{N} 400,[F(1,7)=p=.953]$, e revelou um efeito estatístico de $\mathrm{P} 600,\left[F(2,13)=p^{*}=0.045\right]$.

Analisando os resultados nas janelas do N400 e do P600 em conjunto, podemos dizer que (2b) 'o delegado foi preso pelo ladrão' não é considerada implausível (nenhum N400 foi eliciado) como a condição incongruente (2c). Mas em termos de resposta $\mathrm{P} 600$, a condição (2b) parece estar no meio entre as condições, congruente (2a) e incongruente (2c).

Esses resultados sugerem que, na perspectiva do N400, estímulos na condição ( $2 b$ ) não são entendidos como incongruentes, mas também não são processados, sintaticamente, como sentenças congruentes. Podemos ainda, conforme aventado em nossas hipóteses, que a dicotomia N400-P600 é sim sensível a processos sintático-semânticos e também modulada pela inversão de papéis temáticos. Nós também encontramos evidências que corroboram com a tese de que o N400 reflete processos semânticos e o P600, processos sintáticos.

\section{Conclusão}

Apresentamos a técnica de potenciais relacionado a eventos (EEG-ERP), como uma poderosa ferramenta na investigação do processamento de linguagem on-line. Para ilustrar o uso da técnica, discutimos um estudo sobre o tema da assimetria sujeito-objeto na interface sintaxe-semântica. Este é um dos temas mais debatidos na linguística e psicolinguística atualmente, e a investigação desse tema utilizando EEG-ERP contribui para o melhor entendimento da arquitetura da linguagem na medida em que revela as etapas do processamento de sentenças.

Dois experimentos linguísticos nas vozes ativa e passiva foram relatados com o objetivo geral de relacionar a hipótese teórica da assimetria sujeito-objeto a um novo modelo neurofisiológico de processamento de sentenças, tendo como pano de fundo os achados de testes com ressonância magnética funcional - fMRI/ DTI (Ressonância Magnética Funcional com Difusor de Tensão) que discriminam duas vias distintas de processamento de palavras e sentenças.

Em ambos os experimentos encontramos evidências, que corroboram com a hipótese de que durante a derivação de uma frase como "o delegado prendeu o ladrão", o primeiro DP seria sempre processado pela rota ventral e mantido na memória até que o verbo seja processado, pela via dorsal, com o seu argumento interno. Nossos testes EEG-ERP mostraram que dificuldades de integração dentro do VP tem como resposta bioelétrica um N400 de alta amplitude que se manifesta ainda antes da computação do sujeito. Já integração entre o sujeito (argumento externo) e o complexo verbo-objeto, parece ser uma operação subsequente. Os esforços para integração do sujeito geraram um P600. Esses resultados não parecem suportar a hipótese de que haveria uma interpretação de superfície que guiada pelo conteúdo dos argumentos poderia fazer sentido de sentenças invertidas. Nosso achados parecem apoiar a conclusão de que todos os pequenos passos ao longo da derivação são computacionais, inconscientes e seguem um algoritmo bem definido: "Sintaxe de cima a baixo" (MARANTZ, 1997).

\section{Referências}

BAUMGAERTNER, A.; WEILLER, C.; BÜCHEL, C. Eventrelated fMRI reveals cortical sites involved in contextual sentence integration. NeuroImage, v. 16, n. 3 Pt 1, p. 736-745, jul. 2002.

BEAR, M.; CONNERS, B.; PARADISO, M. Neuroscience: Exploring the Brain. 3. ed. Philadelphia: Lippincott, Williams and Wikins, 2006. p. 858. 
BERWICK, R. C. et al. Evolution, brain, and the nature of language. Trends in cognitive sciences, v. 17, n. 2, p. 89-98, fev. 2013.

CHOMSKY, N. Minimal Recursion: Exploring the prospects. In: ROEPER, T.; SPEAS, M. (Ed.). Recursion. Amherst: [s.n.]. 2012. p. 1-19.

CHOW, W.-Y.; PHILLIPS, C. No semantic illusions in the "Semantic P600" phenomenon: ERP evidence from Mandarin Chinese. Brain research, v. 1506, p. 76-93, 19 abr. 2013.

FRIEDERICI, A. D. et al. The Neural Basis of Recursion and Complex Syntactic Hierarchy. Biolinguistics, v. 5, n. 1, p. 87-104, 2011.

FRIEDERICI, A. D. The brain basis of language processing: from structure to function. Physiological reviews, v. 91, n. 4, p. 1357-1392, out. 2011.

GESUALDI, A. da R.; FRANÇA, A. I. Event-related brain potentials (ERP): an overview. Revista Linguistica, v. 7, n. 2, p. 24-42, 2011.

GOMES, J. N. A direcionalidade no relacionamento semântico: um estudo de ERP. [s.1.]: Universidade Federal do Rio de Janeiro, 2009.

HAGOORT, P. How the brain solves the binding problem for language : a neurocomputational model of syntactic processing. Neuroimage, v. 20, p. 18-29, 2003.

HAGOORT, P.; BROWN, C. M.; GROOTHUSEN, J. The syntactic positive shift (SPS) as an ERP-measure of syntactic processing. Language and Cognitive Processes, v. 8, p. 439-483, 1993.

HOEKS, J. C. J.; STOWE, L. A; DOEDENS, G. Seeing words in context: the interaction of lexical and sentence level information during reading. Brain research. Cognitive brain research, v. 19, n. 1, p. 59-73, Mar. 2004.

KIM, A.; OSTERHOUT, L. The independence of combinatory semantic processing: Evidence from event-related potentials. Journal of Memory and Language, v. 52, n. 2, p. 205-225, Feb. 2005 .

KOLK, H. H. J. et al. Structure and limited capacity in verbal working memory: a study with ERPs. Brain and Language, v. 85, p. 1-36, 2003.

KOS, M. et al. About Edible Restaurants: Conflicts between Syntax and Semantics as Revealed by ERPs. Frontiers in Psychology, v. 1, p. 1-11, Dec. 2010.
KUTAS, M.; FEDERMEIER, K. Electrophysiology reveals semantic memory use in language comprehension. Trends in cognitive sciences, v. 4, n. 12, p. 463-470, Dec. 2000.

KUTAS, M.; HILLYARD, S. Reading Senseless Sentences: Brain Potentials Reflect Semantic Incongruity. Science, v. 207, p. 203-205, Jan. 1980.

KUTAS, M.; HILLYARD, S. Brain potentials durig reading reflect word expenctancy and semantic association. Nature, v. 30, n. 307, p. 161-163, 1984.

LAU, E. F.; PHILLIPS, C.; POEPPEL, D. A cortical network for semantics: (de)constructing the N400. Nature reviews. Neuroscience, v. 9, n. 12, p. 920-33, Dec. 2008a.

LAU, E. F.; PHILLIPS, C.; POEPPEL, D. A cortical network for semantics: (de)constructing the N400. Nature reviews. Neuroscience, v. 9, n. 12, p. 920-933, Dec. 2008b.

LAU, E. et al. The role of structural prediction in rapid syntactic analysis. Brain and language, v. 98, n. 1, p. 74-88, July 2006.

LENT, R. Neurociência da mente e do comportamento. Rio de Janeiro: Guanabara Koogen, 2008. v. 66, p. 374.

LUCK, S. Introduction to the Event-Related Potential Technique. The American journal of tropical medicine and hygiene. Cambridge: MIT, 2005. v. 87.

MARANTZ, A. No Escape from Syntax: Don't Try Morphological Analysis in the Privacy of Your Own Lexicon. University of Pennsylvania Working Papers in Linguistics, v. 4.2, p. 201-225, 1997.

STROUD, C.; C PHILLIPS, C. Examining the evidence for an independent semantic analyzer: An ERP study in Spanish. [s.l]: [s.n.].

VAN HERTEN, M.; KOLK, H. H. J.; CHWILLA, D. J. An ERP study of P600 effects elicited by semantic anomalies. v. 22, p. 241-255, 2005a.

VISSERS, C. T. W. M.; CHWILLA, D. J.; KOLK, H. H. J. The interplay of heuristics and parsing routines in sentence comprehension: evidence from ERPs and reaction times. Biological Psychology, v. 75, n. 1, p. 8-18, Apr. 2007.

Recebido: 31 de agosto de 2014

Aprovado: 07 de novembro de 2014

Contatos: juliana.n.gomes@colorado.edu aniela@gmail.com 